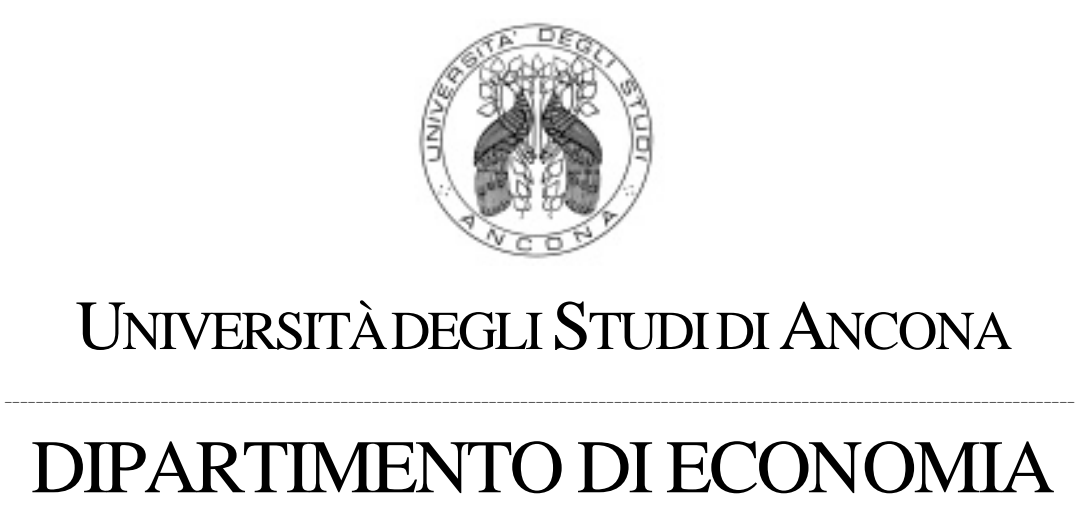

\title{
PUBLIC R\&D INVESTMENT AND COST STRUCTURE IN ITALIAN AGRICULTURE, 1960-1995
}

\author{
Roberto EsPosti, PIERPAOLO PIERANI \\ QUADERNI DI RICERCA n. 176
}

Novembre 2002 
Comitato scientifico:

Renato Balducci

Marco Crivellini

Marco Gallegati

Alessandro Sterlacchini

Alberto Zazzaro 


\title{
PUBLIC R\&D INVESTMENT AND COST STRUCTURE IN ITALIAN AGRICULTURE, 1960-1995
}

\author{
Roberto Esposti $^{*}$ and Pierpaolo Pierani ${ }^{* *}$
}

\begin{abstract}
This article deals with the role of public research in Italian agriculture during the period 1960 to 1995. A short-term specification of the GL cost function capable of accommodating quasi-fixed factors and variable returns is employed. Temporary equilibrium and scale economies are investigated with special emphasis on methodological implications of $R \& D$ stock and consistency of the estimated model with microeconomic theory. Confronting the relevant shadow and rental price the model provides evidence on the topics of under (over) investment and the rationale driving public research expenditure in agriculture A formal test for the induced innovation hypothesis, the calculation of the internal rate of returns and TFP growth decomposition are also considered.
\end{abstract}

\section{J.E.L. Classification: O30, Q16}

Keywords: Public R\&D, R\&D Price, Optimal Investment, Short-Run Cost Function

\footnotetext{
* Department of Economics - University of Ancona, Piazzale Martelli 8, 60121 Ancona Italy

e-mail: robertoe@dea.unian.it, http://www.dea.unian.it/esposti/

** Department of Economics - University of Siena, Piazza S. Francesco 7, 53100 Siena - Italy e-mail: pierani@unisi.it

The authors are listed alphabetically and authorship may be attributed as follows: sections 1,3,5 to Esposti, sections 2, 4 to Pierani.
} 



\section{Index}

1. Introduction ________________________________________ 3

2. Micro foundations and methodological issues _____________ 5

2.1. A simple theory of public R\&D investment_____________ 5

2.2. Public research bias and induced innovation ___________ 9

2.3. Productivity growth decomposition__________________ 11

3. Model specification __________________________________ 13

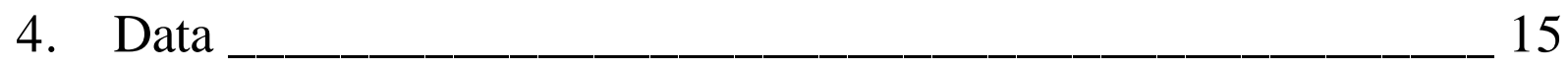

5. Empirical implementation and discussion ________________ 17

5.1 Demand elasticities and induced innovation______________ 19

5.2. Productivity growth decomposition___________________ 21

6. Concluding remarks_________________________________ 22

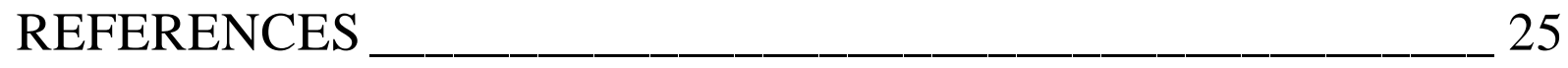

Appendix 33 



\section{Introduction}

This study focuses on the role of public $R \& D$ in applied production analysis, with particular reference to the agricultural sector. An increasing interest has emerged during the recent years over this strand of literature. On the one hand, growth theorists have been elaborating endogenous growth models based on the pivotal role of "public goods", which generate aggregate increasing returns to scale, under perfect competition and price-taking firms at once (Romer, 1990; Griliches, 1995; Jones, 1995; Jones and Williams, 1998). These models increasingly ask for empirical support. On the other hand, the role of public research in enhancing technical progress and output growth in agriculture has stimulated a growing debate in the nineties from the specific perspective of agricultural economists (Echeverria, 1990; Schimmelpfenning et al., 2000). One major reason for this, is the sharp evidence on the high social rate of return to public R\&D (Evenson, 2001), thus suggesting under-investment (Harris and Lloyd, 1991), which apparently contrasts with the reduction of publicly funded research in agriculture observed in a number of developed and developing countries since the second half of the eighties $^{1}$ (Huffman and Just, 1999; OECD, 1995; Rausser, 1999).

In the last decade, a number of applied works explored the aforementioned topics through sectoral models where price-taking (competitive) firms take advantage of non-conventional external factors, which behave as public good. In principle, these empirical studies would allow assessing whether the service flow of this public good can be regarded as optimal from a social perspective (Morrison and Schwartz, 1996a, 1996b; Morrison and Siegel, 1997; Nadiri and Mamuneas, 1994; Mamuneas and Nadiri, 1996). In fact, this strand of literature suffers from two major methodological problems related to the role of public research in production analysis. The first one concerns the real nature of public $R \& D$, since, unlike conventional inputs, the entrepreneur can not control its endowment in farming

\footnotetext{
${ }^{1}$ For a review on public agricultural research funding see Barnes (2001).
} 
activity (in this specific case). The second and related issue deals with expenditure in public research. It is a matter of fact that the rationale behind public research investment is a subtle matter as it concerns a public good able to generate private benefits, e.g. improvement of input productivity. However, for the aforementioned reason, no farmers' optimizing behavior can really account for the investment pattern when a public good is involved. This also rises the question how to define optimal research investment given that its level can significantly differ according to private (farmers) or social (taxpayers) point of view.

One way of dealing with these questions is to imagine a social planner that uses private inputs as farmers would do, and provides the public (R\&D) capital according to its social cost in order to minimize the overall social cost of agricultural production. According to this hypothesis, the optimal public $\mathrm{R} \& \mathrm{D}$ expenditure would depend on some behavioral rule and external variables, mainly prices, including the (social) price/cost of research itself. Under this general framework, not only its own price affects $R \& D$ investment. Also conventional private inputs can influence someway the public R\&D provision, as well as research investment can also affect, via R\&D-induced biases, the conventional inputs use; this is the general idea of the induced innovation hypothesis (Ruttan, 1997; Chavas et al., 1997, Esposti, 2000). Finally, this general framework allows total factor productivity growth to be decomposed into R\&D contribution, returns to scale and unexplained residual.

In this study we assume the existence of a short run aggregate technology for Italian agriculture and depict it from the dual by means of the Generalized Leontief (GL) cost function (Morrison, 1988). This flexible form has been adapted to investigate short run behavior. The restricted cost model accommodates quasi-fixed inputs including public knowledge stock and maintains the consistency of the estimated function with microeconomic theory and approximation properties. The analysis covers the years from 1960 to 1995. The productive technology consists of one aggregate output, three variable inputs (purchased feed, other intermediate inputs, hired labor), three quasi-fixed factors (family labor, physical and R\&D capital). 
The model admits adjustment of the R\&D provision to some long-run social optimal level according to its social price/cost; on this latter point, the paper also pays attention to constructing the relevant research price. The model can provide evidence on three main aspects. Firstly, it can assess whether optimal investment really occurs from the social point of view and provides an estimate of the actual returns to R\&D expenditure. Secondly, it analyses the interaction between $\mathrm{R} \& \mathrm{D}$ stock and conventional inputs in Italian agriculture, also by testing the consistency of the induced innovation hypothesis. Finally, it disentangles the primal productivity growth in its cost-side components, including the contribution of changes in public R\&D stock and of increasing returns to scale generated by the public good.

\section{Micro foundations and methodological issues}

Thanks to developments in duality theory and flexible functional forms, production models can provide relevant information on the role of research in agriculture, particularly with respect to research bias and induced innovation hypothesis, returns to research expenditure and its contribution to increased productivity (Mamuneas and Nadiri, 1996; Morrison and Schwartz, 1996a, 1996b; Morrison and Siegel, 1997, 1998; Nadiri and Kim, 1996; Nadiri and Mamuneas, 1994; Nadiri and Prucha, 1996, 2001). The quality of this information critically depends on the specification of agricultural technology and, consequently, how public research enters the model.

In this respect, though the methodological framework here adopted is not original, it is new for this stream of empirical literature to explicitly apply it to the aforementioned set of issues and hypotheses bringing in public $R \& D$ in agricultural production and technical change.

\subsection{A simple theory of public $R \& D$ investment}

In this study we maintain that farmers minimize the cost of producing a given level of output, conditional on input prices, stocks of quasi-fixed inputs and technological level. Under some regularity 
conditions, duality principles ensure consistency between variable costs and production functions, so that either one will describe the farming activity equally well (Chambers, 1988). The restricted cost function is given by:

$$
\text { (1) } G=G^{*}(W, X, S)
$$

where $\mathrm{G}$ is the minimized variable cost $\mathrm{W}^{\prime} \mathrm{V}, \mathrm{W} \equiv\left(\mathrm{W}_{1}, \ldots, \mathrm{W}_{\mathrm{N}}\right)^{\prime}$ is the price vector of variable inputs $\mathrm{V} \equiv\left(\mathrm{V}_{1}, \ldots, \mathrm{V}_{\mathrm{N}}\right)^{\prime}, \mathrm{X} \equiv\left(\mathrm{X}_{1}, \ldots, \mathrm{X}_{\mathrm{M}}\right)^{\prime}$ is the vector of quasi-fixed factors with user cost $\mathrm{P} \equiv\left(\mathrm{P}_{1}, \ldots, \mathrm{P}_{\mathrm{M}}\right)^{\prime}$, and $\mathrm{S}$ is a vector of exogenous and/or predetermined variables ${ }^{2}$. The latter includes output $\mathrm{Y}$ and time trend $\mathrm{t}$, which is a proxy of exogenous technological level ${ }^{3}$.

The question is what is the proper specification of the cost function in terms of R\&D? Research and extension have economic impacts that typically last for more than one period (Evenson, 2001). Accordingly, one can exclude that inherent services be in equilibrium and hence appear as variable input in the above cost function.

A number of studies consider research activities exogenous; hence, likewise $\mathrm{t}$, appearing among the elements of $\mathrm{S}$. This setting, hardly tenable vis-à-vis private investors, seems more plausible when public institutions are involved (Kuroda, 1997; Mullen at al., 1996; Morrison and Siegel, 1997; 1998). Consequence is, however, that no adjustment to some notional equilibrium level is considered and hence no investment behavior can be inferred.

Alternatively, $R \& D$ is an element of $X \equiv\left(X_{P}, X_{R}\right)$, where $X_{R}$ is public research and $X_{P}$ the vector of the remaining quasi-fixed inputs. This model ascribes a central role to relative prices: in the short run, they determine the demand of variable inputs and, via shadow prices,

${ }^{2}$ The cost function is linearly homogeneous, non-decreasing and concave in $\mathrm{W}$, nondecreasing in $\mathrm{Y}$, non-increasing and convex in $\mathrm{Z}$, non-negative, continuos and twice continuously differentiable in all its arguments.

${ }^{3}$ Here, we follow the working assumption that the ex post output equals the ex ante unobserved output. This hypothesis has important consequences in terms of statistical consistency. Recently, Moschini (2002) has discussed the implications of the output endogeneity within the dual framework. 
contribute towards explaining capacity utilization; in the long run, they determine optimal levels of quasi-fixed factors. The key-element is shadow price, which represents the marginal contribution of $R \& D$ to the reduction in variable cost $\left(-\partial \mathrm{G} / \partial \mathrm{X}_{\mathrm{R}}=\mathrm{Z}_{\mathrm{R}}\right)$.

This assessment rises two questions. Firstly, who is going to carry on the adjustment implied by the difference between marginal and rental price of research capital. Private farmers, not bearing any direct cost for using services of public research, would demand them until the two prices equalize: $\mathrm{Z}_{\mathrm{R}}=\mathrm{P}_{\mathrm{R}}=0$ (Morrison and Schwartz, $1996 \mathrm{~b}$ ). On the other hand, for public institutions social cost (price) of research activities is positive and expenditure decisions will be taken until $Z_{R}=P_{R}>0$ (Morrison and Siegel, 1997). In Italy most of agricultural research at experiment stations, universities and other research centers is public sector responsibility. Hence, it seems reasonable looking at variable cost (1) as behavioral equation of a social planner that considers both public and private inputs and invest in agricultural research so as to satisfy the long run envelope condition $\mathrm{G}+\mathrm{Z}_{\mathrm{P}}^{\prime} \mathrm{X}_{\mathrm{P}}+\mathrm{Z}_{\mathrm{R}} \mathrm{X}_{\mathrm{R}}=\mathrm{G}+\mathrm{P}_{\mathrm{P}} \mathrm{X}_{\mathrm{P}}+\mathrm{P}_{\mathrm{R}} \mathrm{X}_{\mathrm{R}}$. Within such a framework one can measure the discrepancy between actual and steady-state level of R\&D stock (Harris and Lloyd, 1991).

The second point concerns regularity conditions. Specifically, G has to be non-increasing and convex in $R \& D$. In practice, while monotonicity $\left(Z_{R}=-\partial G / \partial X_{R}>0\right)$ is usually satisfied, convexity is more problematic and more often than ever needs to be imposed ${ }^{4}$ While it is obvious to require convexity with respect to private inputs (Mamuneas and Nadiri, 1996; Nadiri and Prucha, 2001; Nadiri and Kim, 1996), we argue that the extension to public R\&D (Mamuneas and Nadiri, 1996) can be questioned. In fact, the implications of a wrong curvature when a public good is involved has never received much attention $^{5}$. Nonconvexities caused by some public good still admitting

4 Sometimes, it happens that this property is also disregarded in discussing results (Mamuneas and Nadiri, 1996; Nadiri and Mamuneas, 1994; Morrison and Schwartz, 1996a; 1996b).

${ }^{5}$ Mundlak (2000, 2001) emphasizes the role of those variables that are not under the farmers' direct control but can still affect production performance. He refers to them as state variables stressing how, in aggregate production models with heterogeneous technologies, 
price-taking competitive firms are unavoidable, at least according to those growth theorists whose work inspires this strand of literature (Romer, 1990). A non-rival and non-excludable public good, like public $R \& D$, justifies nonconvexity of the production set in the form of aggregate increasing returns to scale but can also generate nonconvexities in the input requirement set, therefore increasing marginal returns (Varian, 1992). This possibility shouldn't be ruled out in empirical analysis; nonetheless, it apparently creates a serious methodological problem.

In principle, the dual representation of short run agricultural technology still maintains its validity when $\partial \mathrm{Z}_{\mathrm{R}} / \partial \mathrm{X}_{\mathrm{R}}>0$. In this case, public knowledge stock is fixed and farmers can only change its utilization but not its level. Therefore, variable cost minimization is not influenced by nonconvexity of $\mathrm{G}$ with respect to public $\mathrm{R} \& \mathrm{D}$. However, long-run equilibrium may become meaningless under nonconvexity. As mentioned, long run cost minimization would be achieved when $Z_{R}=P_{R}$. However, this holds only if $\partial Z_{R} / \partial X_{R}<0$; otherwise, the cost minimizing agent (here the social planner) would indefinitely increase the level of $R \& D$ regardless its price.

It must be reminded, though, that long-run level of public research is not necessarily cost minimizing. Under a binding budget constraint (e.g., total public expenditure for agriculture) and possible alternative uses (infrastructure, public education, etc.), provision of public research will not be driven by cost minimization. The social planner would rather allocate the fixed budget in such a way that $\mathrm{Z}_{\mathrm{i}}=\mathrm{P}_{\mathrm{i}}$ for any alternative use $i$, where $P_{i}$ is the social cost/price and $Z_{i}$ the social marginal returns. Meaning that the social planner will allocate total constrained expenditure so that social prices correspond to Lindhal prices (Varian, 1992, p. 426). These prices make the allocation Pareto optimal (Mas-Colell et al., 1995, p. 570). It has been shown that these Lindhal equilibria can exist also in economies with nonconvex production sets (Bonnisseau, 1991).

Under Lindhal equilibrium, the aforementioned envelope

they can justify nonconvexities, though still admitting profit maximizing or cost minimizing farms. 
condition $G+Z_{P}^{\prime} X_{P}+Z_{R} X_{R}=G+P_{P}^{\prime} X_{P}+P_{R} X_{R}$ remains valid since it accounts for private (farmers) cost minimization and public expenditure optimal allocation, at once. Therefore, $Z_{R}=P_{R}$ retains its validity even when $\partial \mathrm{Z}_{\mathrm{R}} / \partial \mathrm{X}_{\mathrm{R}}>0^{6}$. In this case, however, the implied investment behavior is not trivial and, somehow, counterintuitive. Firstly, in the long run we should observe $\partial \mathrm{X}_{R} / \partial \mathrm{P}_{\mathrm{R}}>0$. In the short run, when $Z_{R}>P_{R}$, the social planner will tend to reduce $X_{R}$ and hence we observe over-investment. On the contrary, if $\mathrm{Z}_{\mathrm{R}}<\mathrm{P}_{\mathrm{R}}$, there will be an incentive to increase $X_{R}$, meaning a situation of under-investment. Thus, nonconvexity of $G$ with respect to public $R \& D$ in the empirical analysis can be admitted, and consistently represented in conventional dual production models. However, something really changes in the underlying investment behaviour and, therefore, in the interpretation of under-investment hypothesis. This may affect other public research related issues as well.

\subsection{Public research bias and induced innovation}

The induced innovation hypothesis requires two distinct activities: production and invention. For induced innovation to hold, an input price increase should induce, besides the normal substitution effect, a reduction in the input use through a selective research activity; movement of (along) the Innovation Possibility Curve implies that resources have been devoted to R\&D before any new input-saving production process is introduced (Ruttan, 1997). Therefore, it must be $\partial \ln X_{R} / \partial \ln W_{j}>0$ and $\partial \ln V_{j} / \partial \ln X_{R}<0$ so that $\mathrm{d}\left(\ln \mathrm{V}_{\mathrm{j}}\right) / \mathrm{d}\left(\ln \mathrm{W}_{\mathrm{j}}\right)=\left(\partial \ln \mathrm{X}_{\mathrm{R}} / \partial \ln \mathrm{W}_{\mathrm{j}}\right) \cdot\left(\partial \ln \mathrm{V}_{\mathrm{j}} / \partial \ln \mathrm{X}_{\mathrm{R}}\right)<0$; that is $\mathrm{d}\left(\ln \mathrm{V}_{\mathrm{j}}\right) / \mathrm{d}\left(\ln \mathrm{W}_{\mathrm{j}}\right)<0$ as effect of the research activity (Chavas et al., 1997; Esposti, 2000). These effects can be measured using conventional elasticity coefficients ${ }^{7}$.

${ }^{6}$ Some recent works have also tried to explicitly analyse the consistency of the duality theory under nonconvex technologies and conditional on some quantity/budget constraint (Kuosmanen, 2001). These contributions show that duality may hold also under those conditions, though more research work on the theoretical ground is still needed.

\footnotetext{
7 The mentioned conditions stick to the original Hicksian formulation of the induced innovation hypothesis: "A change in the relative prices of the factors of production is itself a
} 
Short run price elasticities are calculated as $\varepsilon_{\mathrm{ih}}=\partial \ln \mathrm{V}_{\mathrm{i}} / \partial \ln \mathrm{W}_{\mathrm{h}}$, with $\Sigma_{\mathrm{h}} \varepsilon_{\mathrm{ih}}=0, \forall \mathrm{i}$. Concerning scale and capacity induced impacts we have $\varepsilon_{\mathrm{i} Y}=\partial \ln \mathrm{V}_{\mathrm{i}} / \partial \ln \mathrm{Y}$, and $\varepsilon_{\mathrm{ik}}=\partial \ln \mathrm{V}_{\mathrm{i}} / \partial \ln \mathrm{X}_{\mathrm{k}}$, respectively. Shadow price responses are defined analogously, $\varphi_{\mathrm{kh}}=\partial \ln \mathrm{Z}_{\mathrm{k}} / \partial \ln \mathrm{W}_{\mathrm{h}}$, with $\Sigma_{\mathrm{h}} \varphi_{\mathrm{kh}}=1, \forall \mathrm{k}$. These parameters are interpretable as indirect measures of utilization: $\varphi_{\mathrm{kh}}>0$, e.g., means that an increase in $\mathrm{W}_{\mathrm{h}}$ brings about a positive change in $Z_{k}$. Thinking of shadow price as marginal reward of desired stock, its increase materializes in a higher degree of utilization of the relevant asset. On the other hand, flexibilities, $\varphi_{\mathrm{kj}}=\partial \ln Z_{\mathrm{k}} / \partial \ln \mathrm{X}_{\mathrm{j}}$, convey information on the long run behavior of quasi-fixed inputs, the pair being substitute (complement) when $\varphi_{\mathrm{kj}}<0\left(\varphi_{\mathrm{kj}}>0\right)$.

In particular, if $\varphi_{R j}>0$ an increase in $W_{j}$ brings about an increase of $Z_{R}$, which can be interpreted as incentive to invest in research programs. The direction of this incentive, though, depends on the investment behavior that, in turn, influences the long run level $X_{R}^{*}=X_{R}^{*}(W, P, Y, t)$ since this optimal stock is obtained by equalizing shadow and market price $\left(\mathrm{P}_{\mathrm{R}}=\mathrm{Z}_{\mathrm{R}}\right)$.

Combining these elasticities provides information on the induced innovation hypothesis. If convexity holds, i.e. $\varphi_{\mathrm{RR}}<0$ and $\partial \ln X_{R}^{*} / \partial \ln P_{R}<0, \varphi_{R j}>0$ stimulates an increase of research stock in the long run. Under nonconvexity, i.e. $\varphi_{R R}>0$ and $\partial \ln X^{*}{ }_{R} / \partial \ln P_{R}>0, \varphi_{R j}>0$ goes in the opposite direction, i.e., a lower degree of utilization and hence a disincentive to invest. This is so because of the underlying public investor always aims at equalising $P_{R}$ and $Z_{R}$, regardless the sign of $\varphi_{R R}$. In both cases, $\varepsilon_{\mathrm{jR}}$ indicates how the increase in the research effort actually and selectively affects the variable input use. The induced innovation hypothesis, thus, involves both private (input

spur to invention, and to invention of a particular kind - directed to economising the use of a factor which has become relatively expensive" (Hicks, 1932). However, it must be reminded that a full test of the hypothesis should not be restricted to the signs of the mentioned elasticities. It would actually imply also testing for the causality relation between relative price changes, R\&D investment and inputs use (Thirtle et al., 2002). Sings of elasticities are only necessary conditions for the hypothesis to be consistent with data; we mainly concentrate on this aspect. 
use) and public (R\&D investment) choices and the adjustment from short to long run: under convexity, if $\varphi_{\mathrm{Rj}}>0$ (consequently, $\partial \ln X_{R}^{*} / \partial \ln W_{j}>0$ in the long run) and $\varepsilon_{j R}<0$, then the induced innovation hypothesis is consistent in the $\mathrm{j}$-th variable input case; under nonconvexity, induced innovation implies $\varphi_{\mathrm{Rj}}<0$ (so that $\partial \ln \mathrm{X}_{\mathrm{R}}^{*} / \partial \ln \mathrm{W}_{\mathrm{j}}>0$ in the long run) and $\varepsilon_{\mathrm{jR}}=\partial \ln \mathrm{V}_{\mathrm{j}} / \partial \ln \mathrm{X}_{\mathrm{R}}<0$.

Finally, the flexibility $\varphi_{\mathrm{kj}}$ can help in assessing the induced innovation hypothesis in the case of conventional quasi-fixed inputs. Regardless convexity of $\mathrm{G}$ with respect to $\mathrm{R} \& \mathrm{D}$ (but still assuming convexity in conventional quasi-fixed inputs), $\varphi_{\mathrm{k} R}=\partial \ln \mathrm{Z}_{\mathrm{k}} / \partial \ln \mathrm{X}_{\mathrm{R}}<0$ means that an increase of the R\&D stock makes an investment for the $k$-th conventional stock less profitable. If also $\partial \ln X_{R} / \partial \ln P_{k}>0$ in the long run, then the induced innovation hypothesis is consistent for the k-th stock.

\subsection{Productivity growth decomposition}

In this model, the growth of the total factor productivity (TFP) can be decomposed into the exogenous technical change and the other determinants such as capacity utilization (Morrison and Diewert, 1990), scale effects and R\&D contribution (Morrison and Siegel, 1998).

Assuming perfect competition, Ohta (1974) showed that the dual technical change rate $\left(-\varepsilon_{C t}\right)$ equals the primal rate $\left(\varepsilon_{Y t}\right)$ adequately corrected by a scale factor $\left(\varepsilon_{C Y}\right)$ :

(2) $-\varepsilon_{C t}=-\frac{\dot{C}}{C}+\varepsilon_{C Y} \frac{\dot{Y}}{Y}+\sum_{i} S_{i} \frac{\dot{W}_{i}}{W_{i}}=\varepsilon_{C Y} \frac{\dot{Y}}{Y}-\sum_{i} S_{i} \frac{\dot{V}_{i}}{V_{i}}=\varepsilon_{C Y} \varepsilon_{Y t}$

where the dot indicates the time derivative, $S_{i}$ is the i-th variable input total cost share and $\varepsilon_{\mathrm{CY}}=\partial \ln C / \partial \ln \mathrm{Y}, \varepsilon_{\mathrm{Ct}}=\partial \ln \mathrm{l} / \partial \mathrm{t}, \varepsilon_{\mathrm{Yt}}=\partial \ln \mathrm{Y} / \partial \mathrm{t}{ }^{8}$

When some input is quasi-fixed and the relevant stock is not at

\footnotetext{
${ }^{8}$ Only under constant returns to scale, the primal and dual measures are equal in absolute value (if $\varepsilon_{C Y}=1,-\varepsilon_{C}=\varepsilon_{Y t}$ ).
} 
its long run level, equation (2) does not hold anymore. Economic measures of capacity utilization (CU) derive from the comparison between temporary and long run equilibria In particular, a dual indicator of this deviation is given by $\mathrm{CU}=\mathrm{C}^{*} / \mathrm{C}$, where $\mathrm{C}$ is total cost and $\mathrm{C}^{*}$ is total shadow cost, i.e., total cost with quasi fixed inputs evaluated at their shadow prices. Under constant returns to scale, short run cost flexibility and CU coincide (Morrison, 1992): $\mathrm{CU}=1-\sum_{\mathrm{k}} \varepsilon_{\mathrm{Ck}}$ $=\varepsilon_{\mathrm{CY}}$, where $\varepsilon_{\mathrm{CY}}=\partial \ln C / \partial \ln \mathrm{Y}$ and $\varepsilon_{\mathrm{Ck}}=\partial \operatorname{lnC} / \partial \ln \mathrm{X}_{\mathrm{k}}=\left(\mathrm{W}_{\mathrm{k}}-\mathrm{Z}_{\mathrm{k}}\right) \mathrm{X}_{\mathrm{k}} / \mathrm{C}$ are cost flexibility and utilization elasticity, respectively. Using the notion of shadow price, one can determine whether the stock $X_{\mathrm{k}}$ is in excess or falls short of the equilibrium level. In turn, over (CU>1) or under $(\mathrm{CU}<1)$ utilization will be prevailing depending upon the algebraic contribution of each $\varepsilon_{\mathrm{Ck}}$. If shadow and rental prices coincide $\left(\mathrm{W}_{\mathrm{k}}=\mathrm{Z}_{\mathrm{k}}\right), \varepsilon_{\mathrm{Ck}}=0, \forall k$, and capacity is fully utilized $(\mathrm{CU}=1)$.

When variable returns to scale and sub optimal utilization coexist, short run cost flexibility necessarily captures both effects. However, under homotheticity, one can spell the two components out: $\varepsilon_{\mathrm{CY}}=\varepsilon_{C Y}^{L}\left(1-\sum_{\mathrm{k}} \varepsilon_{\mathrm{Ck}}\right)=\varepsilon_{C Y}^{L} \mathrm{CU}$, here $\varepsilon_{C Y}^{L}=\mathrm{d} \ln C / \mathrm{d} \ln \mathrm{Y}=\mathrm{d} \ln \mathrm{X}_{\mathrm{k}} / \mathrm{d} \ln \mathrm{Y}(\forall k)$, i.e., all output elasticities of quasi-fixed inputs are the same and equal to the long run (inverse of) returns to scale, $\varepsilon_{C Y}^{L}$.

Again, however, whenever a public good, as public $R \& D$, is involved and nonconvexity observed the calculation of $\mathrm{CU}_{\mathrm{C}}$ can be critical. As shown, under nonconvexity $\mathrm{P}_{\mathrm{R}}<\mathrm{Z}_{\mathrm{R}}$ indicates shortage of $\mathrm{X}_{\mathrm{R}}$ (that is $X_{R}^{*}>\mathrm{X}_{\mathrm{R}}$ ) and vice versa when $\mathrm{P}_{\mathrm{R}}>\mathrm{Z}_{\mathrm{R}}$. Therefore, in the calculation of $G+Z_{P}^{\prime} X_{P}+Z_{R} X_{R}, Z_{P}$ and $Z_{R}$ (if $\neq P$ ) provides opposite information about capacity utilization, eventually signalling overutilization $\left(\mathrm{C}^{*}>\mathrm{C}\right)$, for instance, when, in fact, is not. Therefore, if nonconvexity is admitted, calculating $\mathrm{CU}_{\mathrm{C}}$ only with regard to the conventional (private) quasi-fixed inputs seems more appropriate.

Equation (2) can be adjusted to have a correct measure of the short-run residual $-\varepsilon_{C t}^{*}$, thus separating the $\mathrm{R} \& \mathrm{D}$ contribution from the exogenous technical change (Morrison and Schwartz, 1996b):

$$
-\varepsilon_{C t}^{*}=\varepsilon_{C Y} \frac{\dot{Y}}{Y}-\sum_{i} S_{i} \frac{\dot{V}_{i}}{V_{i}}-\sum_{k} S_{k}^{*} \frac{\dot{X}_{k}}{X_{k}}
$$


where $S_{k}^{*}=Z_{k} X_{k} / C$, is the k-th stock shadow share on the total cost.

To make the contribution of $R \& D$ to productivity growth emerge clearly, we can combine (3) with the expression of $\varepsilon_{\mathrm{CY}}$. Thus, the traditional (primal) total factor productivity growth measure can be disentangled as follows (Morrison, 1992):

$$
\begin{aligned}
\varepsilon_{Y t} & =-\varepsilon_{C t}^{*}+\left[\left(1-\varepsilon_{C Y}^{L}\right) \frac{\dot{Y}}{Y}\right]+\sum_{k} \varepsilon_{C k}\left[\varepsilon_{k Y} \frac{\dot{Y}}{Y}-\frac{\dot{X}_{k}}{X_{k}}\right]= \\
& =-\varepsilon_{C t}^{*}+\left[\left(1-\varepsilon_{C Y}^{L}\right) \frac{\dot{Y}}{Y}\right]+\sum_{k \neq R} \varepsilon_{C k}\left[\varepsilon_{k Y} \frac{\dot{Y}}{Y}-\frac{\dot{X}_{k}}{X_{k}}\right]+\varepsilon_{C R}\left[\varepsilon_{R Y} \frac{\dot{Y}}{Y}-\frac{\dot{X}_{R}}{X_{R}}\right]
\end{aligned}
$$

Equation (4) shows that the primal productivity growth $\left(\varepsilon_{Y t}\right)$ is the algebraic sum of four distinct effects: the "real" exogenous technical change $\left(-\varepsilon_{C t}^{*}\right)$, the "pure" long run scale effect, the disequilibrium effect due to conventional stock fixity and the disequilibrium effect due to $\mathrm{R} \& \mathrm{D}$ stock fixity9. Therefore, under long run equilibrium, $\varepsilon_{\mathrm{Ck}}=0 \forall \mathrm{k}$, the primal measure corresponds to the dual measure ${ }^{10}$.

\section{Model specification}

Empirically, we depict $\mathrm{G}^{*}$ by means of the Generalised Leontief (GL) form (Morrison, 1988), because it is flexible, in the sense of providing a second-order approximation to an unknown function at any given point (Diewert, 1976). The agricultural technology is described by an aggregate production function, with three variable inputs (inputs for animal productions $\mathrm{V}_{\mathrm{A}}$, inputs for crops $\mathrm{V}_{\mathrm{C}}$, and hired labor $\mathrm{V}_{\mathrm{L}}$ ), three quasi-fixed factors (family labor $\mathrm{X}_{\mathrm{F}}$, physical capital $X_{K}$ and public research $X_{R}$ ) and the disembodied exogenous

\footnotetext{
9 This effect is independent of the convexity of G with respect to R\&D.

${ }^{10}$ See Morrison and Schwartz (1996b) for details.
} 
technical change t. The model estimated is:

$$
\begin{aligned}
& G=Y\left[\sum_{i} \sum_{j} \alpha_{i j} W_{i}^{0,5} W_{j}^{0,5}+\sum_{i} \delta_{i t} t^{0,5} W_{i}+\sum_{i} \delta_{i Y} Y^{0,5} W_{i}+\left(\gamma_{t Y} t^{0,5} Y^{0,5}+\gamma_{Y t} t^{0,5} Y^{0,5}+\gamma_{t} t+\gamma_{Y Y} Y\right) \sum_{i} W_{i}\right]+ \\
& Y^{0,5}\left[\sum_{i} \sum_{k} \delta_{i k} W_{i} X_{k}^{0,5}+\sum_{i} W_{i} \sum_{k} \gamma_{t k} X_{k}^{0,5} t^{0,5}+\sum_{i} W_{i} \sum_{k} \gamma_{Y k} X_{k}^{0,5} Y^{0,5}\right]+\sum_{i} W_{i} \sum_{k} \sum_{l} \gamma_{k l} X_{k}^{0,5} X_{l}^{0,5}
\end{aligned}
$$

For econometric implementation, a set of cost-minimizing variable input demands can be derived based on Shephard's lemma. Here, optimal input-output coefficients are considered to reduce possible heteroskedasticity:

$$
V_{i} / Y=(1 / Y) \partial G(.) / \partial W_{i}+u_{i} \quad(\mathrm{i}=\mathrm{A}, \mathrm{C}, \mathrm{L})
$$

System (6) contains all the relevant parameters; hence, we needn't provide an enlarged set of equations. However, greater efficiency in estimation can be gained by forcing more structure on the data, e.g., including additional information such as marginal cost or shadow value equations. The latter ones represent the potential reduction in variable cost from an additional unit of quasi-fixed input $\left(-\partial \mathrm{G} / \partial \mathrm{X}_{\mathrm{k}}=\mathrm{Z}_{\mathrm{k}}\right)$. Variable returns to scale prevent from equating the residual measure of returns to multiple quasi-fixed inputs $\left(\mathrm{P}_{\mathrm{Y}} \mathrm{Y}-\mathrm{G}\right.$, where $\mathrm{P}_{\mathrm{Y}}$ is output price) with shadow fixed cost, $\sum \mathrm{F}_{\mathrm{k}} \mathrm{Z}_{\mathrm{k}}$ (Morrison, 1988). So, for estimation purposes, we decided for the former alternative:

(7) $P_{Y}=\partial G / \partial Y+u_{Y}$

Parameter estimates are obtained using iterative Zellner techniques ${ }^{11}$ under the typical assumption that $u_{i}$ and $u_{Y} \mathrm{v}_{\text {ift }}$ are i.i.d. error terms.

Based on estimated parameters and analytical expressions of derivatives, one can compute all the relevant measures concerning the technology of Italian agriculture. Moreover, we can calculate the marginal internal rate of returns (MIRR) to public research in the short run and compare it with the long run MIRR (Thirtle and Bottomley,

11 The command used is LSQ of TSP 4.5, whose option HETERO computes standard errors which are consistent even in the presence of unknown heteroskedasticity (White, 1980). 
1989; Schimmelpfenning et al., 2000). The short run MIRR is obtained as follows:

$$
\sum_{n=0}^{L_{R}} \frac{w_{n} Z_{R, t-L_{R}}}{(1+I R R)^{n}}=1
$$

where $L_{R}$ is the maximum length for research investment effects and $w_{n}$ is the weight of age/efficiency function over the $L_{R}$ period (Esposti and Pierani, 2002). In the long run, the marginal value equals marginal productivity, hence MIRR is derived as follows:

(9) $\sum_{n=0}^{L R} \frac{w_{n} Y_{t-n}^{*} \varepsilon_{Y R, t-n}}{X_{R, t-L}^{*}(1+I R R)^{n}}=1$

where $\varepsilon_{Y R, t-n}=\partial \ln Y^{*} / \partial \ln X_{t-n}$.

\section{Data}

Rental price of knowledge capital plays a major role in the depicted model (Morrison - Schwartz, 1996b). Firstly, the nominal R\&D expenditure have to be correctly deflated to allow intertemporal comparison on a real base. This is the problem of the Investment Price Index (IPI), which has always to be calculated either when the R\&D enters the model as exogenous shifter or quasi-fixed factor. Secondly, if research enters as quasi-fixed input and the social planner point of view is considered, the calculation of an appropriate R\&D stock user cost (that is $P_{R}$ ) is needed and it requires the construction of a Stock Price Index (SPI).

The problem of the R\&D IPI has been already raised in the literature. Many studies use the GDP deflator or the Consumer Price Index when no alternative index is available (Morrison and Siegel, 1997; Thirtle and Bottomley, 1989) ${ }^{12}$. However, it is largely acknowledged that the composition of research expenditure relevantly differs from the composition of national product. The use of the GDP

12 Using the GDP deflator as IPI for research is a frequent practice also in the official statistics, as in the Italian case (ISTAT, various years). 
deflator can thus significantly bias the real R\&D effort (Mansfield et al., 1983). A proper IPI has to be based on the actual composition of the $R \& D$ expenditure that can, in turn, change over sectors and over different kinds of research effort (basic, applied, developmental). Mansfield (1984; 1987) calculates an R\&D IPI based upon a survey on 100 manufacturing firms; Nadiri and Kim (1996) uses the JaffeGriliches R\&D deflator for the US private non-farm business sector. However, these indices could not necessarily be adequate for agricultural sector and public R\&D. Dealing with the public R\&D capital, Nadiri and Mamuneas (1994) use the price deflator of government purchases of goods and services. For the agricultural public R\&D, Pardey et al. (1989) and Bengston (1989) define a specific IPI based on the expenditures composition of the State Agricultural Experimental Stations.

In this study we follow this general idea to estimate the specific IPI for the Italian public agricultural R\&D expenditure composition ${ }^{13}$. By applying this R\&D deflator, it emerges that the GDP deflator overestimates the real research investment increase: the average annual growth during the period 1960-1995 is 6,4\% when the GDP deflator is used, while it is $5,1 \%$ with the IPI. This confirms previous results (Griliches, 1984; Mansfield 1984 and 1987).

The SPI is affected by the IPI but does not coincide with it. In fact, the implicit $R \& D$ stock price at time $t$ is the cost beard to hold one unit of stock in that year. This user cost is determined by three components (Caiumi et al., 1995; Nadiri and Kim, 1996): the opportunity cost of invested money, capital gains or losses caused by inflation, and capital depreciation. Jorgenson (1989) proposes, for physical capital, a specification of the user cost that can be written as follows:

$$
\text { (10) } S P I_{t}=I P I_{t-1}\left[r_{t}-\pi_{t}+\left(1+\pi_{t}\right) \rho_{t}\right]
$$

where $r$ is the interest rate, $\pi$ is the expected capital gain (or loss) rate due to inflation, and $\rho$ is the $\mathrm{R} \& \mathrm{D}$ stock depreciation rate. In equation (10), $I P I_{t-1}\left(r_{t}-\pi_{t}\right)$ expresses in real terms the opportunity cost

\footnotetext{
${ }^{13}$ For the sake of space we skip the detailed procedure, which is available upon request.
} 
of a unit of invested capital, while $\operatorname{IPI}_{t-1}\left(1+\pi_{t}\right) \rho_{t}$ is the depreciation corrected for inflation.

The public agriculture R\&D investment here considered include all the public expenditure (Government, Public University, Regions, and other public research institutions) and is described in Esposti and Pierani (2000). The R\&D stock series (figure 1) have been calculated from the investment series using the parameters calculated in Esposti and Pierani (2002) where also the R\&D stock depreciation rate is reported; this is also needed for the calculation of the user cost SPI (figure 1). Inflation and interest rates are taken from AGRIFIT. Finally, for the calculation of the IPI, the salary index for the R\&D labor has been taken from Franco (1993), while the investment price index comes from AGRIFIT. The fixed weights among research sources and inputs have been taken from ISTAT (various years).

Other information regarding conventional inputs is taken from AGRIFIT database on Italian agriculture (Caiumi et al., 1995). These data cover the period 1960-1995.

\section{Empirical implementation and discussion}

The estimated GL restricted cost function $^{14}$ is monotonic in W and $\mathrm{Y}$ (non-decreasing) and the three stocks (non-increasing), concave in prices and convex in conventional quasi-fixed inputs at all sample points. Concerning knowledge stock, the estimated function is found to be convex only in a few years, while it violates the second-order property at the sample mean, which is the approximation point (Table 3 ). The $\mathrm{R}^{2}$ goodness of fit varies between 0.87 for animal inputs demand and 0.99 for marginal cost equation.

Table 1 assembles temporary equilibrium indicators. Since CU depends on utilization elasticities, the ratios between shadow and the rental price are also reported. Figure $2^{15}$ clearly shows that Italian

\footnotetext{
${ }^{14}$ Parameter estimates and approximated standard errors are reported in Appendix.

${ }^{15}$ As mentioned in section 2.3 , since $\partial \ln Z_{R} / \partial \ln X_{R}>0$, it is more appropriate to calculate CU taking into account only conventional quasi-fixed factors. However, considering also R\&D
} 
agriculture moves from over to under utilization around 1980, indicating some underlying structural adjustment in the production structure and investment strategy. Different behaviors characterize conventional quasi fixed inputs between periods. Physical capital moves from over to under utilization while family labor is always in excess, particularly in the second period. Therefore, both the constant decline of family labor and the constant growth of investment in physical capital in Italian agriculture can be interpreted as the adjustment to long-run levels. The adjustment is somewhat partial in the case of labor while, on the contrary, we observe over-adjustment in the case of capital. The different pattern of conventional stocks with respect to long-run equilibrium levels, eventually explain the overall CU indicating only a $7 \%$ excess of production capacity during the whole period.

According to the price ratio, $R \& D$ stock partially follows the path of physical capital. However, due to nonconvexity $\left(\partial \ln Z_{R} / \partial \ln X_{R}>0\right)$ the interpretation is opposite. For public R\&D stock, we observe underutilization (i.e. overinvestment) in the first subperiod and large overutilization (i.e. underinvestment) in the second one. The interpretation of this result derives from the underlying investment behavior. From a social point of view, if the social planner pursues a Lindhal equilibrium for the alternative uses of some given amount of public expenditure, the long run equilibrium is reached when $Z_{R}=P_{R}>0$, regardless convexity. Therefore, when $Z_{R}>P_{R}$ and $\partial \ln Z_{R} / \partial \ln X_{R}>0$, a reduction in $X_{R}$ is needed, that is over investment is observed. This happens until the eighties, while the opposite holds in the last fifteen years. In any case, the $\mathrm{Z}_{\mathrm{R}} / \mathrm{P}_{\mathrm{R}}$ ratio is, on average, evidently less than one (about 0.6 ) over the whole period indicating an overall underinvestment.

Since $\mathrm{G}$ is monotonic (decreasing) with respect to $\mathrm{R} \& \mathrm{D}$ (i.e. $\mathrm{Z}_{\mathrm{R}}<0$ over the whole sample), it follows that returns to research are positive $^{16}$. Therefore, the MIRR can be correctly computed from

fixity would affect capacity measure very little due to the low value of $\boldsymbol{\varepsilon}_{C R}$.

\footnotetext{
16 Though this result may seem trivial, it must be noticed that negative returns are sometimes reported in the empirical literature (Alston et al., 2000).
} 
equation (8) and (9) using estimated shadow prices and elasticities. The calculation is based on a 20-years maximum length of the research effects (Schimmelpfenning et al., 2000); therefore, data of period 1976-95 are considered. Table 2 clearly indicates that the returns computed with the short-run cost function is much lower than the hypothetical returns that would be observed under the long run equilibrium. The short-run measure is, indeed, the real observed return and is much lower than the average estimates reported in the literature (Alston et al., 2000). A 4,2\% seems a plausible return if compared to other long-run investment; in fact, though the R\&D expenditure could be considered as a risky one, the expected risk premium is probably low in the case of public expenditure compared to private investment. It must be also noticed that such a low return does not contrast with observed underinvestment. Conventionally, underinvestment is associated to high returns but this holds only when $\partial \ln Z_{R} / \partial \ln X_{R}<0$. In this case, since $\partial \ln Z_{R} / \partial \ln X_{R}<0$, having low returns is consistent with the incentive to increase the public R\&D provision; when this happen, that is in the long run equilibrium, the hypothetical returns are actually higher, as expected.

\subsection{Demand elasticities and induced innovation}

Table 3 reports variable input and shadow price elasticities ${ }^{17}$. On the whole, input use is more responsive to scale of production than prices, so that short run changes in factor proportions mainly depend on output level. Own- and cross-price coefficients are accurately estimated and much smaller than unity, which imply a rather rigid structure. The direct responses of feeds and other inputs (including fertilizer) are comparatively low, indicating that the feeding strategy and hence the production of forage are, to some extent, fixed for a single production year. The own price elasticity of hired labor (-.44) shows a relatively higher degree of responsiveness. Cross effects show

\footnotetext{
${ }^{17}$ Given that results do not show marked variations, for the sake of space we discuss only sample mean estimates. In estimation, analytical derivatives and approximated standard errors are obtained through the TSP commands DIFFER and ANALYZ, respectively.
} 
that hired labor substitutes for the other two inputs that, in turn, behaves as complement.

The table also reports elasticities with respect to output and quasi-fixed inputs. Because of variable returns, scale elasticities do not resemble each other; e.g., a unit increase in output has a stronger effect on hired labor (1.8) and feeds (1.4), whereas other input is the least responsive (.4). Adjustment to capacity is mixed; however, it clearly emerges that the role of $R \& D$ on input demands is almost negligible if compared with capital stock and family labor. In particular, public research substitutes for both purchased feeds $(-.01)$ and other inputs (-.03), which together make up more than 50\% of variable costs (table 5), whereas is complement of hired labor (.01). Capital, which includes breeding livestock, and feeds are complement (.23); finally, family labor substitute for animal inputs (-1.61) and behaves as complement of other inputs (.28) and hired labor (.14), but this latter effect is not statistically significant at $90 \%$. Most of these adjustments are modest and within the range of price effects, with few exceptions.

For the symmetry relationships pertaining to the twice continuos differentiability of cost functions we have that quasi-fixed input demand elasticities and shadow price elasticities do share similar information $^{18}$. E.g., since self employed farmers substitute for feeds, an increase of their market prices makes the marginal productivity value of family labor increase (more than proportionally) in the short run. The opposite holds with other input price and hired labor wage. Responses are normally higher for research capital. In particular, its quasi rent, and thus utilization, increases more than proportionally with other input price (1.95), whereas wage $(-1.71)$ has a negative impact. Finally, cross flexibilities seem to suggest R\&D be complement with the other two quasi-fixed factors.

Recalling non convexity of the estimated GL with respect to knowledge stock and relevant discussion, previous results seem to

\footnotetext{
${ }^{18}$ Namely, $\partial \mathrm{V}_{\mathrm{i}} / \partial \mathrm{X}_{\mathrm{k}}=-\partial \mathrm{Z}_{\mathrm{k}} / \partial \mathrm{W}_{\mathrm{i}}$, which can be re-phrased in terms of elasticities as: $\varepsilon_{\mathrm{ik}}=-$ $\left(\omega^{*} / \omega_{\mathrm{k}}^{*}\right) \varphi_{\mathrm{ki}}$, where $\omega_{\mathrm{i}}^{*}$ and $\omega_{\mathrm{k}}^{*}$ are the input shares on shadow cost $C^{*}$, and $\varphi_{\mathrm{ki}}$ gives the impact of $\mathrm{W}_{\mathrm{i}}$ on the quasi rent of stock $\mathrm{k}$.
} 
reject the induced innovation hypothesis for either variable or conventional quasi-fixed inputs. A tentative explanation is that public research bias may be driven by specific social and/or political objectives rather than market forces (Esposti, 2000); e.g., maintaining a significant amount of workers within the agricultural sector.

Whether non convexity with respect to research has been already encountered in applied literature is difficult to say, as authors not always report on curvature properties of their estimated cost functions (Mamuneas and Nadiri, 1996; among others). In general, non convexity is disturbing in that undermines micro foundations for the existence of an equilibrium $\left(\mathrm{Z}_{\mathrm{R}}=\mathrm{P}_{\mathrm{R}}\right)$. As marginal returns are not decreasing, cost minimizers with unlimited resources would find convenient to invest in public R\&D indefinitely. Notwithstanding, such an eclectic result may become sensible if one is willing to assume the existence of a social planner facing an expenditure constraint and aiming at an optimal allocation of her budget among alternative uses, which include agricultural research.

\subsection{Productivity growth decomposition}

Table 4 reports the decomposition of primal productivity growth. It appears that, in the whole period, variable cost has declined at $1.4 \%$ per annum, meaning that some productivity growth is still unexplained. Results also show that, when public research is among quasi-fixed factors, increasing returns to scale can prevail at the aggregate level; in fact, cost flexibility $\varepsilon_{C Y}^{L}$ varies between 0.7 and 0.8 , meaning a scale elasticity of about 1.35 . Increasing returns would attenuate the primal productivity growth measure $\varepsilon_{Y t}$.

However, productivity decomposition is also affected by quasifixed factor utilization. As emerges from table 4, while the effect of $R \& D$ disequilibrium is negligible, much more relevant are the conventional stocks. In particular, considering the whole period, the physical capital eventually corrects the primal measure upward while family labor downward. Collecting all the components, the primal productivity growth turns out to be lower by $0.4 \%$ per year. 
Generally, the advancement of knowledge manifests itself in a non neutral manner; such a bias is measured by the rate of change in factor proportions, $B_{i}=\partial \ln \omega_{i} / \partial t, \forall i$. Recalling that GL demand functions are expressed in terms of input level, it can easily be seen that: $\mathrm{B}_{\mathrm{i}}=\varepsilon_{\mathrm{it}}-\varepsilon_{\mathrm{Gt}}$, where $\varepsilon_{\mathrm{it}}=\partial \ln \mathrm{X}_{\mathrm{i}} / \partial \mathrm{t}$ and $\varepsilon_{\mathrm{Gt}}=\partial \operatorname{lnG}(.) / \partial \mathrm{t}$ is the rate of reduction in variable cost over time. The semi elasticities $\varepsilon_{\mathrm{it}}$ 's are not independent of one another, in that $\varepsilon_{\mathrm{Gt}}=\Sigma_{\mathrm{i}} \omega_{\mathrm{i}} \varepsilon_{\mathrm{it}}$ and, consequently, $\Sigma_{\mathrm{i}} \omega_{\mathrm{i}} \mathrm{B}_{\mathrm{i}}=0$. Technological change is defined to be input $i$-using $\left(\mathrm{B}_{\mathrm{i}}>0\right)$, saving $\left(B_{i}<0\right)$, or neutral $\left(B_{i}=0\right)$, depending on whether relative change in input $i$ is larger, smaller or the same as the rate of cost reduction, respectively. When all inputs are affected equiproportionally, i.e., $\mathrm{B}_{\mathrm{i}}=0, \forall i$, overall neutrality is implied.

From table 5, the bias turns out to be relatively using of both other inputs (.028) and, to a lesser degree, hired labor (.008) and economizing in feeds and other animal inputs (-.041). The semi elasticities indicate that the advancement of knowledge has had statistically significant impacts on factor intensities, independently of both relative prices and scale adjustments. We normally expect the $\varepsilon_{\mathrm{it}}$ 's to be negative since their weighted sum equals $\varepsilon_{\mathrm{Gt}}$. However, some of them may well be positive. This is the case with other inputs (.014); while hired labor (-.006) and especially feeds (-.055) register negative rates of change. The complementarity (substitution) of hired labor (animal feeds) with knowledge stock is coherent with estimated biases. Results are at odds, instead, with other inputs, whose technological bias does not seem to be in accordance with the given R\&D capacity (table 3 ).

\section{Concluding remarks}

This paper aims to analyse the role of the public $R \& D$ expenditure in the Italian agriculture with major reference to its long run equilibrium level and the consequent under (over) investment hypothesis, the interaction with the conventional private farm inputs and the contribution to productivity growth and returns to scale. The study uses an econometric model taking into account the public good nature of this input as well its endogenous long run optimal level. This 
model allows to explicitly testing the hypothesis of over or underinvestment in public agricultural $R \& D$ by calculating an appropriate public research price index. The study would benefit from longer time series of public R\&D investment and prices. Moreover, the appropriate calculation of the $\mathrm{R} \& \mathrm{D}$ stock price would require more detailed information about the sources and composition of the research spending. Further research effort in data analysis and construction is therefore needed.

A critical point emerging from the empirical results is related to the public R\&D investment behavior underlying the long run equilibrium levels. In particular, the short-run cost function here adopted is nonconvex with respect to public R\&D making the usual long run minimisation assumption meaningless. However, from the theoretical point of view, nonconvexity is not a surprising result when a public good is concerned and other public investor's behaviour could be actually admitted making the long run equilibrium still meaningful. Under this alternative interpretation, the Italian agriculture shows over-investment in public R\&D in the sixties and seventies, while this investment becomes largely inadequate in the eighties and nineties. In any case, this is clearly an issue to which applied production analysts, from both theoretical and empirical ground, may wish to pay more attention in future research.

The empirical evidence also suggests that, whenever the partial equilibrium in R\&D stock endowment is admitted, the estimated returns are lower than $5 \%$, thus much more plausible if compared to alternative investment with similar associated risk. It also emerges that induced innovation hypothesis is not actually supported for any conventional input. Results confirm that public R\&D stock contributes in generating increasing returns to scale at the sectoral level. Moreover, it is also possible to disentangle primal productivity growth. Even when the impact of the R\&D expenditure, the scale and the capacity utilization effects are appropriately admitted and separated, there is still a significant space left to the exogenous time trend on both the cost reduction and inputs use. This result also indicates that other sources of agricultural innovations should be considered more in detail. In particular, intersectoral and international 
spillovers, both private and public, could explain technical change besides (or together with) the national public agricultural R\&D (Mamuneas and Nadiri, 1996). Some steps in this direction have been taken in analysing the Italian agriculture case (Esposti, 2002). However, so far, data available for spillovers calculation, do not allow long enough time series to be included in the model here adopted. 


\section{REFERENCES}

Alston, J.M., Marra, M.C., Pardey, P.G. e Wyatt, T.J. (2000). Research returns redux: A meta-analysis of the returns to agricultural R\&D. The Australian Journal of Agricultural and Resource Economics, Vol. 44, 185-215.

Barnes, A.P. (2001). Towards a framework for justifying public agricultural R\&D: the example of UK agricultural research policy. Research Policy, 30, 663-672.

Bengston, D.N. (1989). A price index for deflating state agricultural experiment station research expenditures. The Journal of Agricultural Economics Research, 41 (4), 12-20.

Bonnisseau, J. (1991). Existence of Lindhal equilibria in economies with nonconvex production sets. Journal of Economic Theory, 54, 409-416.

Caiumi, A., Pierani, P., Rizzi, P.L., Rossi, N. (1995). AGRIFIT: una banca dati del settore agricolo (1951-1991). Franco Angeli, Milano.

Chambers, R.G. (1988): Applied Production Analysis. A Dual Approach. Cambridge University Press, Cambridge.

Chavas, J.P., Aliber, M. T.L. Cox (1997). An Analysis of the Source and Nature of Technical Change: the Case of U.S. Agriculture. Review of Economics and Statistics, 79(3), 482-492.

Echeverria, R. (ed.) (1990). Methods for diagnosing research system constraints and assessing the impact of agricultural research. The Hague: ISNAR

Esposti, R. (2000). The impact of public R\&D and Extension expenditure on Italian agriculture. An Application of a Mixed Parametric/Nonparametric Approach. European Review of Agricultural Economics, 27 (3), 365-384.

Esposti, R. (2002). Public agricultural R\&D design and technological spill-ins. A dynamic model. Research Policy, 31 (5), 693-717. 
Esposti, R. e Pierani, P. (2002). Building the knowledge stock: lags, depreciation and uncertainty in R\&D investment and link to productivity growth. Journal of Productivity Analysis (forthcoming).

Esposti, R., Pierani, P. (2000). Modelling Technical change in Italian Agriculture: a Latent Variable Approach. Agricultural Economics, Vol. 22, n. 3, pp. 261-270.

Evenson, R.E. (2001). Economic impacts of agricultural research and extension. In: Gardner-Rausser (eds.): Handbook of Agricultural Economics-Vol. 1 A, North-Holland, 573-628.

Franco, D. (1993). L'espansione della spesa pubblica in Italia. Bologna: Il Mulino.

Griliches, Z. (1984). Comment. In Z. Griliches, $R \& D$, Patents and Productivity, National Bureau of Economic Research, Chicago: University of Chicago Press.

Griliches, Z. (1995). R\&D and productivity: econometric results and measurement issues. In Stoneman, P., Handbook of the economics of innovation and technological change, Oxford: Blackwell, 52-89.

Harris, M., Lloyd, A. (1991). The Returns to Agricultural Research and the Underinvestment Hypothesis. A Survey. Australian Economic Review, 95, July-Sept. 1991, 16-27.

Hicks, J.R. (1932).The Theory of Wages, London: Macmillan.

Huffman, W.E., Just, R.E. (1999). The organization of agricultural research in western developed countries, Agricultural Economics, Vol. 21, pp. 1-18.

ISTAT (various years). Statistiche della ricerca scientifica $e$ dell'innovazione tecnologica, Roma.

Jones, C.I. (1995). R\&D-based models of economic growth. Journal of Political Economy, 103 (4), 759-84.

Jones, C.I., Williams, J.C. (1998): Measuring the social return to R\&D. Quarterly Journal of Economics, 113 (4), 1119-1135.

Kuosmanen, T. (2001). Duality Theory of Non-convex Technologies. Paper presented at the Exclusive Workshop on DEA, 21-22 September, Odense University, Denmark. 
Kuroda, Y. (1997). Research and extension expenditures and productivity in Japanese agriculture, 1960-1990, Agricultural Economics, Vol. 16, n. 2, 111-124.

Mamuneas, T.P., Nadiri, M.I. (1996): Public R\&D policies and cost behaviour of the US manufacturing industries. Journal of Public Economics, 63 (1), 57-81.

Mansfield, E. (1984). R\&D and innovation: some empirical findings. In Z. Griliches, $R \& D$, Patents and Productivity, National Bureau of Economic Research, Chicago: University of Chicago Press.

Mansfield, E. (1987). Price indexes for R\&D inputs, 1969-1983. Management Science, 33 (1), 124-129.

Mansfield, E., Romeo, A., Switzer, L. (1983). R\&D price indices and real R\&D expenditures in the United States. Research Policy, 12 (2), 105-112.

Mas-Colell, A., Whinston, M., Green, J.R. (1995). Microeconomic theory. New York: Oxford University Press.

Morrison, C.J. (1988). Quasi-Fixed Inputs in U.S. and Japanese Manufacturing: A Generalized Leontief Restricted Cost Function Approach. Review of Economics and Statistics, 70, 275-287.

Morrison, C.J. (1992). A micreconomic approach to the measurement of economic performance. Springer-Verlag, New York.

Morrison, C.J., Diewert, W.E: (1990): New techniques in the measurement of multifactor productivity. Journal of Productivity Analysis, 1.

Morrison, C.J., Schwartz, A.E. (1996a). Public infrastructure, private input demand, and economic performance in New England Manufacturing. Journal of Business \& Economic Statistics, 14 (1), 91101.

Morrison, C.J., Schwartz, A.J. (1996b). State infrastructure and productive performance. The American Economic Review, vol. 86, n.5,1095-1111.

Morrison, C.J., Siegel, D. (1997). External factors and increasing returns in U.S. manufacturing. The Review of Economics and 
Statistics, vol. 79, n. 4, 647-654.

Morrison, C.J., Siegel, D. (1998). Knowledge capital and cost structure in the US food and fiber industries. American Journal of Agricultural Economics, 80 (1), 30-45.

Moschini, G. (2002) Production risk and the estimation of exante cost functions, Journal of Econometrics, 100, 357-380.

Mullen, J.D., C.J. Morrison, L. Strappazzon (1996). Modelling technical change in Australian broadacre agriculture using a translog cost model, Paper presented at the Georgia Productivity Workshop II, University of Georgia, November 1-3.

Mundlak, Y. (2000). Agriculture and economic growth. Theory and Measurement. Cambridge, Mass.: Harvard University Press.

Mundlak, Y. (2001). Production and supply. In: GardnerRausser (eds.): Handbook of Agricultural Economics-Vol. 1A, NorthHolland, 3-85.

Nadiri, M.I., Kim, S. (1996). R\&D, Production Structure and Productivity Growth: A Comparison of the US, Japanese, and Korean Manufacturing Sectors. NBER Working Paper: 5506.

Nadiri, M.I., Mamuneas, T.P. (1994). The Effects of Public Infrastructure and R\&D Capital on the Cost Structure and Performance of U.S. Manufacturing Industries. Review of Economics and Statistics, 76(1), 22-37.

Nadiri, M.I., Prucha, I.R. (1996). Estimation of the depreciation rate of physical and R\&D capital in the U.S. total manufacturing sector. Economic Inquiry, 34(1), 43-56.

Nadiri, M.I., Prucha, I.R. (2001). Dynamic factor demand models and productivity analysis. In Hulten, C.R., Dean, E.R., Harper, M.J (eds.), New developments in productivity analysis, NBER Studies in Income and Wealth. Volume 63, 103-164.

OECD (1995). Technological change and structural adjustment in OECD agriculture. Paris.

Ohta, M. (1974): A note on the duality between production and cost functions: Rate of return to scale and rate of technical progress. 
Economic Studies Quarterly, 25.

Pardey, P.G., Craig, B., Hallaway, M.L. (1989). U.S. agricultural research deflators: 1890-1985. Research Policy, 18 (5), 289-296.

Rausser, G. (1999). Private/Public research: knowledge assets and future scenarios. American Journal of Agricultural Economics, 81 (5), 1011-1027.

Romer, P.M. (1990). Are Nonconvexities Important for Understanding Growth? American Economic Review, 80(2), 97-103.

Ruttan, V.W. (1997). Induced Innovation, Evolutionary Theory and Path Dependence: Sources of Technical Change. Economic Journal, 107, 1520-1529.

Schimmelpfenning, D., Thirtle, C., van Zyl, J., Arnade, C., Khatri, Y. (2000). Short and long-run returns to agricultural R\&D in South Africa, or will the real rate of return please stand up? Agricultural Economics, 23, 1-15.

Thirtle, C., Bottomley, P. (1989). The rate of return to public sector agricultural R\&D in the UK, 1965-80. Applied Economics, 21, 1063-1086.

Thirtle, C., Schimmelpfenning, D., Townsend, R.F. (2002). Induced innovation in United States agriculture, 1880-1990: time series tests and an Error Correction Model. American Journal of Agricultural Economics, 84 (3), 598-614.

Varian, H.R. (1992). Microeconomic analysis. $3^{\text {rd }}$ edition. New York: W.W. Norton Company.

White, H. (1980). A Heteroskedasticity-Consistent Covariance Matrix and a Direct Test for Heteroskedasticity. Econometrica, 48, 721-746. 
Table 1: Dual measures of capacity utilization by period (at the sample mean - approximated std. errors in parenthesis)

\begin{tabular}{ccccc}
\hline Period & $\mathrm{CU}_{\mathrm{C}}$ & $\mathrm{Z}_{\mathrm{R}} / \mathrm{P}_{\mathrm{R}}$ & $\mathrm{Z}_{\mathrm{K}} / \mathrm{P}_{\mathrm{K}}$ & $\mathrm{Z}_{\mathrm{F}} / \mathrm{P}_{\mathrm{F}}$ \\
\hline $1960-81$ & 1.038 & 1.511 & 1.502 & .926 \\
& $(.014)$ & $(.093)$ & $(.069)$ & $(.039)$ \\
$1981-95$ & .902 & 0.414 & .765 & .769 \\
& $(.007)$ & $(.086)$ & $(.018)$ & $(.015)$ \\
$1960-95$ & .928 & .592 & 1.155 & .635 \\
& $(.013)$ & $(.089)$ & $(.055)$ & $(.036)$ \\
\hline
\end{tabular}

Table 2: Agricultural R\&D marginal internal rate of returns (MIRR) under alternative hypotheses

\begin{tabular}{lc}
\hline Hypothesis & MIRR(\%) \\
\hline Short run & 4.2 \\
Long run & 170 \\
Mean of public and private (1772 estimates) & 74 \\
\hline
\end{tabular}

Table 3: Variable input and shadow price elasticities (at the sample mean - approximated std. errors in parenthesis)

\begin{tabular}{cccccccc}
\hline $1960-95$ & $\mathrm{~W}_{\mathrm{A}}$ & $\mathrm{W}_{\mathrm{C}}$ & $\mathrm{W}_{\mathrm{L}}$ & $\mathrm{X}_{\mathrm{R}}$ & $\mathrm{X}_{\mathrm{K}}$ & $\mathrm{X}_{\mathrm{F}}$ & $\mathrm{Y}$ \\
& & & & & & & \\
\hline Animal inputs & -.311 & -.058 & .369 & -.010 & .230 & -1.613 & 1.394 \\
$\left(\mathrm{~V}_{\mathrm{A}}\right)$ & $(.007)$ & $(.001)$ & $(.009)$ & $(.004)$ & $(.112)$ & $(.149)$ & $(.170)$ \\
Other inputs & -.059 & -.328 & .387 & -.026 & -.156 & .280 & .429 \\
$\left(\mathrm{~V}_{\mathrm{C}}\right)$ & $(.001)$ & $(.004)$ & $(.004)$ & $(.004)$ & $(.072)$ & $(.066)$ & $(.125)$ \\
Hired labor & .215 & .221 & -.436 & .013 & -.774 & .139 & 1.758 \\
$\left(\mathrm{~V}_{\mathrm{L}}\right)$ & $(.029)$ & $(.030)$ & $(.060)$ & $(.004)$ & $(.098)$ & $(.094)$ & $(.161)$ \\
$\mathrm{R} \& \mathrm{D}$ & .760 & 1.954 & -1.714 & 1.497 & 2.261 & 1.287 & -1.423 \\
$\left(\mathrm{Z}_{\mathrm{R}}\right)$ & $(.439)$ & $(.449)$ & $(.766)$ & $(.511)$ & $(.643)$ & $(.590)$ & $(1.132)$ \\
Capital & -.184 & .122 & 1.061 & .024 & -1.166 & -.115 & .648 \\
$\left(\mathrm{Z}_{\mathrm{K}}\right)$ & $(.083)$ & $(.057)$ & $(.080)$ & $(.005)$ & $(.155)$ & $(.185)$ & $(.246)$ \\
Family labor & 1.468 & -.251 & -.217 & .015 & -.131 & -.408 & .397 \\
$\left(\mathrm{Z}_{\mathrm{F}}\right)$ & $(.175)$ & $(.059)$ & $(.171)$ & $(.007)$ & $(.209)$ & $(.309)$ & $(.529)$ \\
\hline
\end{tabular}


Table 4: Productivity growth decomposition by period (at the sample mean)

\begin{tabular}{c|c|c|cc|cc|cc|c}
\hline Period & $-\varepsilon_{C t}^{*}$ & $\varepsilon_{C Y}^{L}$ & \multicolumn{2}{c|}{ Family labor } & \multicolumn{2}{c|}{ Capital } & \multicolumn{2}{c}{ R\&D } & $\varepsilon_{\mathrm{Yt}}$ \\
& & & $\varepsilon_{\mathrm{CF}}$ & $\varepsilon_{\mathrm{CF}} \varepsilon_{\mathrm{FY}}$ & $\varepsilon_{\mathrm{CK}}$ & $\varepsilon_{\mathrm{CK}} \varepsilon_{\mathrm{KY}}$ & $\varepsilon_{\mathrm{CR}}$ & $\varepsilon_{\mathrm{CR}} \varepsilon_{\mathrm{RY}}$ & \\
\hline $1960-80$ & .020 & .794 & .023 & .021 & -.059 & -.028 & -.001 & .000 & .014 \\
$1981-95$ & .014 & .714 & .045 & .038 & .050 & .020 & .002 & .001 & .012 \\
$1960-95$ & .014 & .797 & .096 & .081 & -0.026 & -.013 & .002 & .001 & .010 \\
\hline
\end{tabular}

Table 5: Cost shares, technological biases and variable input rates of change (at the sample mean - approximated std. errors in parenthesis)

\begin{tabular}{cccc}
\hline & $\omega_{\mathrm{i}}$ & $\mathrm{B}_{\mathrm{i}}$ & $\varepsilon_{\mathrm{it}}$ \\
\hline Animal & .270 & -.041 & -.055 \\
inputs & $(.021)$ & $(.005)$ & $(.005)$ \\
Other & .266 & .028 & .014 \\
inputs & $(.014)$ & $(.003)$ & $(.003)$ \\
Hired labor & .464 & .008 & .006 \\
& $(.036)$ & $(.003)$ & $(.004)$ \\
Weighted & 1 & 0 & -.014 \\
sum & & & $(.001)$ \\
\hline
\end{tabular}


Figure 1: Public agricultural R\&D stock in Italy (billions of 1985 Italian Lire) and user cost

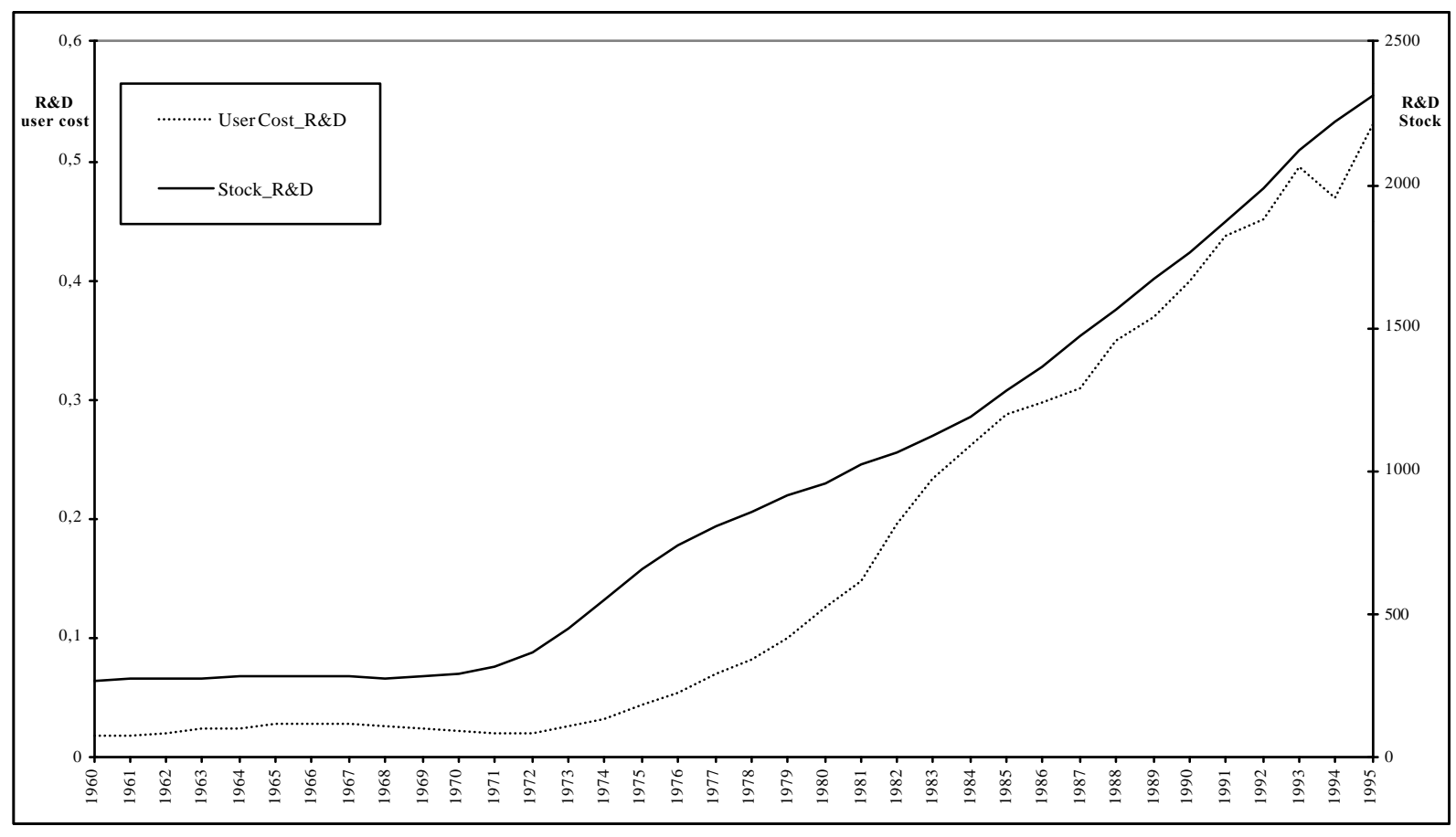

Figure 2: Dual capacity utilization (at the sample mean)

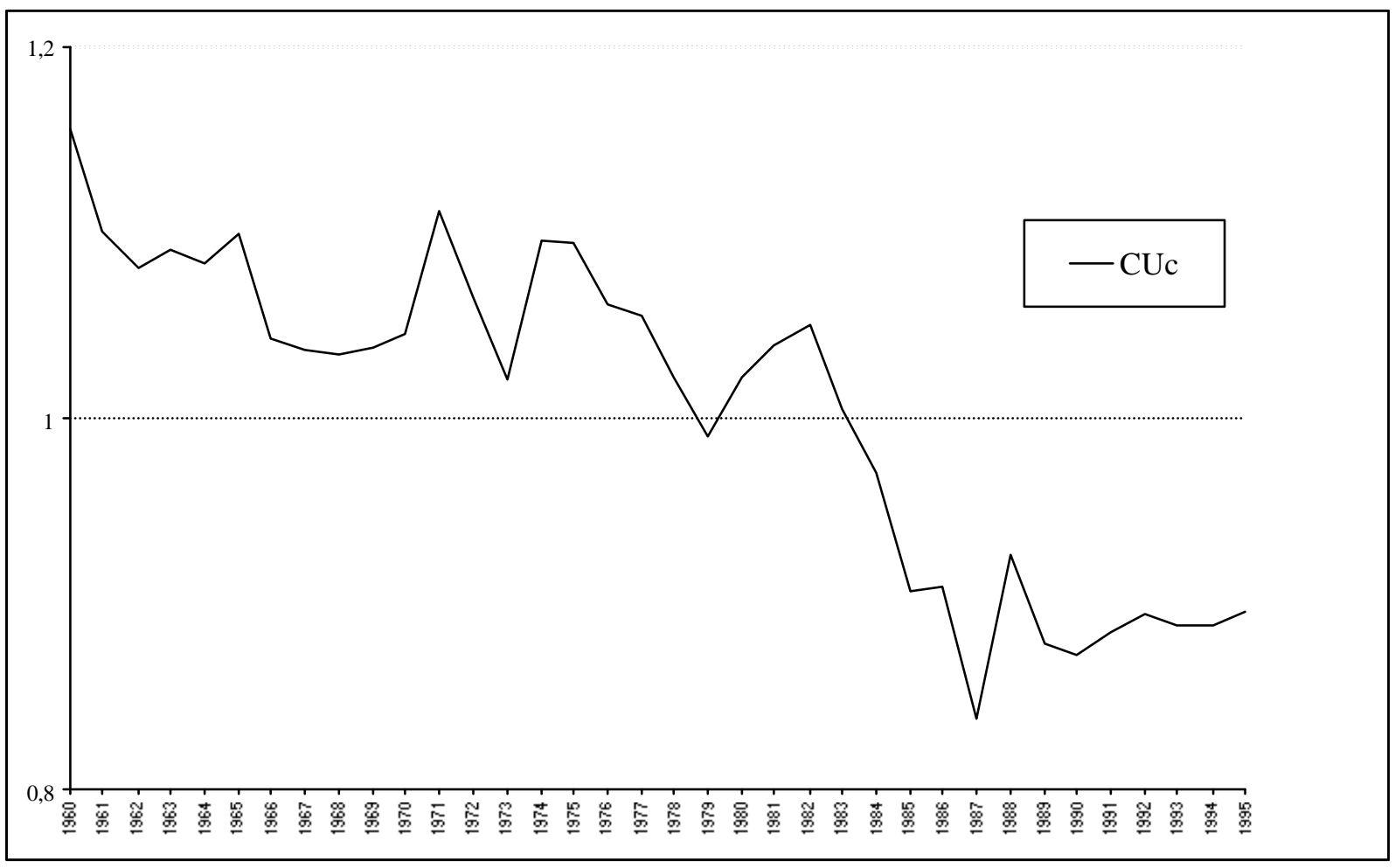


Appendix

Parameter estimates of the GL variable cost function

\begin{tabular}{ccc|ccc}
\hline Parameter & Estimate & Std. Error & Parameter & Estimate & Std. Error \\
\hline$\alpha_{\mathrm{AA}}$ & 0.8837 & 0.1492 & $\delta_{\mathrm{CF}}$ & 0.0357 & 0.2158 \\
$\alpha_{\mathrm{AC}}$ & -0.0380 & 0.0132 & $\delta_{\mathrm{CK}}$ & -0.2347 & 0.0515 \\
$\alpha_{\mathrm{AL}}$ & -0.0022 & 0.0278 & $\delta_{\mathrm{CR}}$ & 0.0817 & 0.0282 \\
$\alpha_{\mathrm{CC}}$ & 0.3739 & 0.1906 & $\delta_{\mathrm{LF}}$ & 0.2246 & 0.2241 \\
$\alpha_{\mathrm{CL}}$ & 0.0727 & 0.0155 & $\delta_{\mathrm{LK}}$ & -0.4022 & 0.0555 \\
$\alpha_{\mathrm{LL}}$ & 0.6887 & 0.2080 & $\delta_{\mathrm{LR}}$ & 0.1820 & 0.0346 \\
$\delta_{\mathrm{At}}$ & -0.0470 & 0.0939 & $\gamma_{\mathrm{Ft}}$ & -0.0961 & 0.0727 \\
$\delta_{\mathrm{Ct}}$ & 0.0582 & 0.1033 & $\gamma_{\mathrm{Kt}}$ & 0.0633 & 0.0158 \\
$\delta_{\mathrm{Lt}}$ & -0.1481 & 0.1110 & $\gamma_{\mathrm{Rt}}$ & -0.0069 & 0.0098 \\
$\delta_{\mathrm{AY}}$ & -0.0009 & 0.0003 & $\gamma_{\mathrm{FY}}$ & 0.0000 & 0.0002 \\
$\delta_{\mathrm{CY}}$ & -0.0003 & 0.0004 & $\gamma_{\mathrm{KY}}$ & 0.0003 & 0.0001 \\
$\delta_{\mathrm{LY}}$ & 0.0003 & 0.0004 & $\gamma_{\mathrm{RY}}$ & -0.0002 & 0.0001 \\
$\gamma_{\mathrm{tY}}$ & -0.0001 & 0.0001 & $\gamma_{\mathrm{FF}}$ & -0.0290 & 0.0848 \\
$\gamma_{\mathrm{tt}}$ & -0.0237 & 0.0221 & $\gamma_{\mathrm{FK}}$ & 0.0077 & 0.0196 \\
$\gamma_{\mathrm{YY}}$ & 0.0001 & 0.0000 & $\gamma_{\mathrm{FR}}$ & -0.0202 & 0.0093 \\
$\delta_{\mathrm{AF}}$ & -0.4403 & 0.2126 & $\gamma_{\mathrm{KK}}$ & 0.0244 & 0.0049 \\
$\delta_{\mathrm{AK}}$ & -0.1901 & 0.0482 & $\gamma_{\mathrm{KR}}$ & -0.0124 & 0.0025 \\
$\delta_{\mathrm{AR}}$ & 0.1380 & 0.0227 & $\gamma_{\mathrm{RR}}$ & -0.1202 & 0.0144 \\
\hline $\mathrm{Std}$ & & & & \\
\hline
\end{tabular}

Std. errors computed from quadratic form of analytic first derivatives (delta method).

Glossary of parameter subscripts: $\mathrm{A}=$ animal inputs, $\mathrm{C}=$ other inputs, $\mathrm{L}=$ hired labor, $\mathrm{Y}=$ output, $\mathrm{t}=$ trend, $\mathrm{F}=$ family labor, $\mathrm{K}=$ capital, $\mathrm{R}=\mathrm{R} \& \mathrm{D}$ 